\section{PALAVRAS-CHAVE}

- Educação em Saúde.

- Educação Médica.

- Docentes de Medicina.

- Avaliação Educacional.

\title{
Avaliação do Perfil dos Professores de Medicina de uma Universidade do Interior de Minas Gerais
}

\section{Assessment of Medical Faculty Profile at a University in Minas Gerais, Brazil}

\author{
Vinícius Torres Leite ${ }^{I}$ (DD \\ Paulo Ítalo Faria Lima Vazzi ${ }^{I}$ (D) \\ Marcos Barbosa Rodrigues de Moura ${ }^{I}($ D \\ Larissa Santos Pereira ${ }^{I}$ (iD) \\ Theóphilo de Paiva Caldas Neto ${ }^{I}$ (D) \\ Eduardo Henrique de Matos Lima ${ }^{I}$
}

\section{RESUMO}

Introdução: $O$ ensino médico vem passando por grande reformulação nas últimas décadas, e um dos pontos considerados fundamentais nessa mudança é a atuação docente. Pesquisas indicam que os professores de Medicina usualmente possuem pouca formação didático-pedagógica, dividem-se entre as profissões de médico e professor, colocada em segundo plano, privilegiam a pesquisa em relação ao ensino e são resistentes a mudanças no seu modo de atuação. Segundo a literatura, essas características repercutiriam diretamente no ensino oferecido. Método: A presente pesquisa buscou analisar como características dos professores de Medicina de uma universidade no interior de Minas Gerais repercutem na forma como os alunos avaliam o ensino recebido. Para tanto, levantou-se o perfil dos professores a partir de documentação e entrevista semiestruturada. Posteriormente, os alunos avaliaram os professores participantes por meio de um questionário autoaplicado. Confrontaram-se avaliação e perfil, e utilizaram-se testes estatísticos para a análise da associação entre características e avaliação feita. Participaram 57 professores (83,8\% dos elegíveis) e 203 alunos (84,5\% dos elegíveis). Resultados: Foi identificado perfil de professores semelhante ao da literatura, com a maioria em dedicação parcial à universidade, renda proporcionada principalmente por outra profissão e preparação didática constituindo parte reduzida da formação. A comparação entre os grupos de características dos professores, com base nas avaliações dos alunos, por sua vez, mostrou resultados que rompem com a bibliografia. Os dados mostraram, com relevância estatística, que no curso professores mais jovens, com menos tempo de graduação, de atuação docente e de experiência em outra profissão, sem mestrado e que possuem como motivação para lecionar prazer e aptidão são mais bem avaliados. Maior tempo de preparação didática, cursos preparatórios, maior dedicação semanal ao ensino e maior identificação com a docência, entre outros aspectos, não se associam à melhor avaliação de forma estatisticamente significativa. Conclusões: A pior avaliação do docente mais experiente, associada a questões como conflitos geracionais e dificuldades de adaptação a novos currículos, mostra a importância de uma preparação docente contínua e reforçada com o tempo. Além disso, o melhor desempenho de professores mais satisfeitos demonstra a importância da valorização da carreira docente. Por fim, constata-se que quantidade de formação não é suficiente sem qualidade nessa formação.

${ }^{\mathrm{I} U n i v e r s i d a d e ~ F e d e r a l ~ d e ~ S a ̃ o ~ J o a ̃ o ~ d e l-R e i, ~ D i v i n o ́ p o l i s, ~ M i n a s ~ G e r a i s, ~ B r a s i l . ~}$ 


\section{KEYWORDS}

- Health Education.

- Education Medical.

- Medical Faculty.

- Educational Evaluation.

\section{ABSTRACT}

Introduction: Medical education has undergone a major overhaul over the last decades and one significant change is related to teaching performance. Research indicates that the medical faculty typically has little training in didactics, split their time between clinical practice and teaching, award less priority to the latter, privileging research to the detriment of teaching, and resist changing their ways. According to the literature, such traits and attitudes would directly affect educational quality. Method: This study assessed how traits and attitudes of the medical faculty at a university in Minas Gerais impact student assessment of the education they receive. For that purpose, teachers were profiled through semi-structured interviews and analysis of relevant documentation. Subsequently, students assessed their teachers' performance through a self-applied questionnaire. Performance and profiles were then compared, and statistical tests were used to analyze the associations between teachers' traits and performance assessment results. Overall, 57 faculty members (83.8\% of those eligible) and 203 students (84.5\% of those eligible) participated in this study. Results: A faculty profile similar to that found in the literature was identified, with a majority of teachers dedicating only part of their time to the university, and most of their income coming from another occupation and teacher training amounting to a small portion of their overall professional training. The analyses of relationships between groups of traits and teaching performance, however, contradicted the literature. The data showed, with statistical relevance, that younger teachers and those who graduated a shorter time ago, who are less experienced in teaching or have other occupations, who lack a master's degree and whose motivation to teach comes from satisfaction and vocation are better evaluated. Longer didactical training, undergoing training courses, longer weekly dedication and greater identification with the teaching profession are not significantly associated with better evaluation. Conclusion: The worse evaluation of the most experienced faculty, associated with issues such as generational conflicts and difficulties adapting to new curricula, shows the importance of continuous faculty training and updating. Additionally, the better performance of more satisfied teachers, demonstrates the importance of valuing the teaching career and raising its status. Finally, it seems that more teacher training is not enough in itself and more attention must be paid to the training quality.

Recebido em 23/4/20

Aceito em 10/6/20

\section{INTRODUÇ̃̃O}

Um esforço global se iniciou nos últimos 40 anos visando à transformação da forma como é ensinada a Medicina. Uma série de movimentos iniciados na década de 1970 passou a combater o modelo flexneriano em vigor, biologicista e restrito a uma ideia de saúde-doença unicausal, centrado no hospital e com estimulação à especialização e fragmentação do ensino, buscando sua substituição por um modelo com visão mais ampla da Medicina e da forma como ela é ensinada, com espaços para dimensões sociais, psicológicas e econômicas ${ }^{1-4}$.

Esses movimentos culminaram na Declaração de Edimburgo de 1988, que trazia propostas significativas em busca da humanização do profissional médico, além de mudanças para um currículo que adotasse metodologias de ensino mais ativas e maior integração com a comunidade ${ }^{5,6}$. No Brasil, signatário da declaração, adotou-se uma série de medidas para a modificação do ensino da Medicina, como a criação da Comissão Interinstitucional de Avaliação do Ensino Médico (Cinaem), que avaliou mudanças a serem propostas nos currículos ${ }^{1,7}$, e, a partir das propostas, a edição das Diretrizes Curriculares Nacionais (DCN) para o ensino médico de $2001^{8}$ e $2014^{9}$ e programas de incentivo a reformas curriculares, como o Programa Nacional de Incentivo às Mudanças Curriculares nos Cursos de Medicina (Promed $)^{10}$ e o Programa Nacional de Reorientação da Formação Profissional em Saúde (Pró-Saúde) ${ }^{11}$. Paralelamente, a Associação Brasileira de Educação Médica (Abem) avaliou o ensino e as medidas tomadas, e, com base nisso, deu subsídios para as tentativas de modificação ${ }^{12,13}$.
A necessidade de novos métodos de ensino, que já eram princípios da Declaração de Edimburgo, foi reforçada em todas as etapas citadas, e os professores de Medicina foram apontados como um dos principais focos de atenção e o desenvolvimento docente como o elemento de mais difícil modificação. A Cinaem, em seus relatórios, identificou um baixo preparo dos docentes para ensino e a necessidade de mudanças no perfil dos professores existente até então ${ }^{1}$. O perfil traçado nos relatórios seria "estruturado predominantemente pela dedicação parcial às atividades de ensino, menor fração constitutiva da renda mensal proveniente da atividade docente, perfil de titularidade mais comum centrado na pósgraduação senso lato (residência médica) e escassa preparação didático-

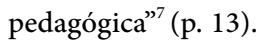

As DCN de 2001 determinavam que o projeto pedagógico deveria ser construído "centrado no aluno como sujeito da aprendizagem e apoiado no professor como facilitador e mediador do processo ensino-aprendizagem" (artigo $9^{\circ}$ ). Já os programas de incentivo, em sua fundamentação, eram críticos ao enfoque pedagógico que "limita-se às metodologias tradicionais baseadas na transmissão de conhecimentos, que não privilegiam a formação crítica do estudante, inserindo-o tardiamente no mundo do trabalho"11 (p. 8). As avaliações promovidas pela Abem, por sua vez, identificaram que as faculdades se percebiam como inovadoras com tendências avançadas, mas com o desenvolvimento docente muito abaixo de outros eixos avaliados e a abordagem pedagógica também em um patamar inferior ${ }^{12,13}$. Já a Comissão da Câmara de Educação, em parecer que fundamentou as DCN de 2014, trouxe a constatação de que "docentes das profissões da saúde necessitam

REVISTA BRASILEIRA DE EDUCAÇ̄̃̃ MÉDICA

2 44(3) : e096; 2020 
de preparação e reflexão específicas na área da educação, muito além do que as disciplinas de 'metodologia do ensino superior' e 'didática' que os mestrados e doutorados propiciam" (p. 12).

Essa visão negativa sobre o desenvolvimento docente é compartilhada por diversos autores e pesquisas. Como aponta $\operatorname{Costa}^{14}$ :

Publicações referentes à docência médica $e$ à docência universitária são unânimes ao considerarem a existência de uma deficiência no domínio da área educacional, no desempenho do docente do ensino superior. Praticamente não existe, nas escolas médicas, preparo específico para os professores no campo pedagógico (p. 23).

Segundo a autora, existiriam cinco fatores limitantes para as mudanças na atuação do docente em Medicina: desvalorização das atividades de ensino e supremacia da pesquisa; falta de profissionalização docente; desvalorização da formação docente do professor de Medicina; resistência do docente a mudanças; e individualismo da ação docente ${ }^{14}$. As dificuldades dos docentes seriam fruto não só de uma falta de estímulo por parte de governos e instituições de ensino, mas também do próprio perfil do professor que teria peculiaridades que dificultam seu desenvolvimento como educador.

Pesquisas mostram que, ao entrar na faculdade, o discente não tem como alvo tornar-se professor, e, ao longo do curso, essa possibilidade não é estimulada ${ }^{15,16}$. A vontade de lecionar surgiria posteriormente não pelo interesse em ensinar, mas pela busca por status ou complementação de renda. Uma vez professores, também não são incentivados a aprimorar a própria formação ${ }^{12}$, exceto pela realização de mestrados e doutorados, que possuem pouco conteúdo voltado para docência e, além de não repararem a deficiência em didática ${ }^{16}$, estimulam um terceiro foco de atenção: a pesquisa ${ }^{17}$. $\mathrm{O}$ docente não se vê como professor, mas sim como médico, algo que também não colabora para que ele procure formas de se capacitar ${ }^{14}$. Sem a capacitação adequada, os docentes encontram dificuldades para colocar em prática as mudanças propostas pelos novos currículos, muitas delas baseadas em teorias avançadas de educação que ele desconhece e não virá a conhecer, por priorizar a pesquisa ou a carreira principal ${ }^{18}$.

Embora se tenha bem definido na literatura a dificuldade que o desenvolvimento docente representa para a transformação do ensino médico no país e como o perfil do professor de Medicina contribui para essa dificuldade, poucas pesquisas buscaram identificar em que medida cada uma das características que compõem esse perfil contribuiria para um pior desempenho do professor nas atividades de ensino. A Lei de Diretrizes e Bases da Educação Nacional $(\mathrm{LDB})^{19}$, no único artigo dedicado à formação do professor universitário, coloca, de um lado, o mestrado e o doutorado como as fontes principais de preparação para o magistério superior e, de outro, o notório saber, que poderia suprir a especialização. As instituições de ensino, seguindo as diretrizes, acabam contratando com base nesses elementos ${ }^{20}$. Todavia, não há dados que demonstrem que o professor doutor teria uma capacidade maior de ensino que os demais ou que o professor com vasta experiência profissional na área ensinada teria maior capacidade didática para tratar do assunto. Não se sabe se características como maior experiência, formação mais ampla, maior tempo de dedicação ou maior interesse pela docência, por exemplo, tornariam alguém um melhor professor ou quais dessas características seriam preponderantes nesse aspecto.

O presente estudo busca preencher essa lacuna e, a partir de um estudo de caso do curso de Medicina da Universidade Federal de São João del-Rei (UFSJ), câmpus Centro-Oeste Dona Lindu (CCO), objetiva avaliar em que medida professores de Medicina se enquadram nas características que são apontadas na literatura e quais as consequências delas na forma como a atuação docente é percebida na universidade.

\section{MÉTODOS}

Realizou-se pesquisa de natureza aplicada, com abordagem quantitativa, com fins exploratórios e descritivos, seguindo as metodologias de uma pesquisa do tipo estudo de caso e adotando instrumentos diversos para a coleta e análise de $\operatorname{dados}^{21-23}$. A unidade de estudo foi o curso de Medicina da UFSJ, câmpus CCO, e a pesquisa teve como objetivo analisar em que medida características relativas à formação, atuação e motivação dos professores afetariam a forma como são avaliados pelos alunos.

A coleta de dados foi realizada em quatro etapas: pesquisa bibliográfica; levantamento de dados dos professores a partir de análise documental; levantamento de dados dos professores por meio de entrevista semiestruturada; e levantamento da avaliação dos alunos sobre o ensino recebido por meio da aplicação de questionário aos alunos do curso de Medicina.

$\mathrm{Na}$ pesquisa bibliográfica, levantou-se o perfil dos professores de Medicina brasileiros para o estabelecimento de características em comum que foram avaliadas nos professores da unidade de estudo na etapa seguinte. Posteriormente, fez-se o levantamento do perfil dos professores da unidade a partir de análise documental e realizou-se entrevista estruturada com eles, na qual constavam questões relativas à formação, à atuação profissional e aos fatores de motivação para a docência.

$\mathrm{Na}$ última etapa de coleta de dados, os alunos do segundo ao nono período do curso foram convidados a responder a um questionário sobre como avaliam o desempenho geral dos professores com os quais tiveram aula. Nesse questionário, avaliaram-se todos os professores que autorizaram de forma expressa sua participação. Os professores foram avaliados pelos alunos por meio de uma abordagem unidimensional, com a utilização de pergunta única de caráter global, de forma a simplificar os cálculos, sem perda de efetividade do instrumento e possibilitando um questionário mais curto, de modo a prevenir que respostas fossem afetadas pelo desgaste dos alunos.

Dos 68 professores da unidade de estudo, 57 aceitaram participar, respondendo ao questionário e aceitando a avaliação discente. Com relação aos demais, um não foi contatado, três se desligaram da universidade, três entraram em licença médica/maternidade, dois não tinham horários acessíveis e três não responderam aos contatos feitos. As entrevistas foram realizadas ao longo do ano de 2018.

Com o consentimento dos professores para participar da pesquisa, elaboraram-se os questionários de avaliação aplicados aos alunos no final de 2018. Dos 240 alunos que cursavam entre o segundo e o nono período, 203 aceitaram participar da pesquisa.

Processaram-se os dados no programa Microsoft Excel 365. Com base nos dados quantitativos, realizou-se a distribuição de frequência das variáveis estudadas, e as respostas às perguntas abertas foram submetidas à análise. A partir das prevalências das variáveis identificadas nos questionários aplicados aos professores, traçou-se o perfil deles que

REVISTA BRASILEIRA DE EDUCAÇC̃̃ MÉDICA

3 44 (3) : e096; 2020 
posteriormente foi confrontado com o identificado na literatura.

Com base na avaliação feita pelos alunos, calculou-se a nota média atribuída a cada professor. Posteriormente, os professores foram agrupados a partir de cada uma das variáveis em estudo, e, com isso, pôde-se calcular a média de notas associadas com cada uma das características identificadas. Os dados foram submetidos a testes paramétricos e não paramétricos, nos quais se utilizou o programa RStudio, e, assim, avaliaram-se as características que teriam uma melhor relação com avaliações altas ou baixas.

O projeto de pesquisa foi submetido previamente ao Comitê de Ética em Pesquisa da UFSJ, Certificado de Apresentação para Apreciação Ética/ Sistema Nacional de Informação sobre Ética envolvendo Seres Humanos (CAAE/Sisnep) n ${ }^{\circ}$ 80776417.3.0000.5545, e aprovado nos termos do Parecer $n^{\circ} 2.529 .143 / 2018$, emitido em 6 de março de 2018. A pesquisa foi realizada com respeito aos preceitos éticos estabelecidos pelo comitê.

\section{RESULTADOS}

Perfil dos professores

O perfil dos professores da unidade de estudo foi traçado a partir de três conjuntos principais: formação, atuação e motivação. Além da análise do conjunto dos professores, os dados também foram considerados separadamente para aqueles dos ciclos básico e clínico, tendo em vista a discrepância apontada na literatura entre os dois perfis: os primeiros não formados em Medicina e muito envolvidos com pesquisa, e os demais são, em geral, médicos que exercem a docência paralelamente à carreira médica. Os dados encontrados corroboram em grande parte aqueles identificados na bibliografia ${ }^{1,7,12,14-18,20}$.

Quanto à formação, a maior parte dos professores (64\%) se graduou em Medicina, em universidade públicas (73\%) e nas décadas de 1990 e 2000 ( $30 \%$ e $49 \%$, respectivamente). Durante a graduação, $74 \%$ não cursaram disciplinas voltadas para o preparo para a docência, dos quais $43 \%$ entendiam que o preparo não seria necessário durante a graduação. Ao contrário do apontado na literatura, $60 \%$ dos docentes manifestaram interesse pela docência durante a graduação, dos quais $65 \%$ a viam como carreira principal. Quando consideramos os dois grupos de professores, os números são discrepantes, com apenas $9 \%$ dos professores de clínica declarando ter recebido preparação para a docência ao longo de sua graduação, com uma média de 15 horas, contra $55 \%$ dos professores de bases, com uma média de 345 horas de preparação. Entre os professores de clínica, apenas $23 \%$ tinham a intenção de seguir a docência como carreira principal durante a graduação.

Com relação à especialização, a pós-graduação stricto sensu é comum entre os professores (70\%), em frequência que se aproxima das especializações lato sensu (77\%). O curso possui $67 \%$ dos professores com título de mestre e $49 \%$ com título de doutor. Quanto aos cursos específicos para a preparação didático pedagógica, como programas de educação permanente, cursos de preceptoria e capacitações de professores, $41 \%$ os realizaram. Quanto ao tempo da especialização dedicado a aulas preparatórias para a docência, no mestrado $54 \%$ dos professores não tiveram nenhuma aula sobre o tema e $41 \%$ tiveram até 60 horas voltadas para abordagem do assunto. Já no doutorado, $64 \%$ não tiveram horas dedicadas à docência, enquanto $27 \%$ tiveram até 60 horas sobre o tema. Como esperado, a pós-graduação stricto sensu é mais comum entre professores do ciclo básico (95\%) do que entre aqueles do ciclo clínico (54\%), enquanto a pós-graduação lato sensu é priorizada pelo segundo grupo ( $97 \%$ contra $45 \%$ dos professores de bases).

Sobre o total de horas dedicadas à preparação para a docência ao longo de toda a formação, considerando graduação, especializações e cursos, $45 \%$ têm mais de 200 horas de preparo, 36\% têm entre uma e 200 horas e $18 \%$ não tiveram, em nenhum momento de sua formação, instruções sobre o tema. Quando perguntados se achavam que o preparo havia sido suficiente, $55 \%$ entendiam que sim. Questionados sobre onde ou como haviam aprendido a ensinar, entre as respostas que mais se repetiram, $53 \%$ citaram a prática em sala de aula, $12 \%$ mencionaram cursos preparatórios, $12 \%$ apontaram que seria uma habilidade inata e 9\% responderam que o preparo se baseou nos professores que tiveram durante formação. As diferenças entre as médias de horas dedicadas à formação para a docência são mostradas no Gráfico 1 .

No segundo conjunto de dados, referentes à atuação profissional, observam-se professores com relativamente pouca experiência na educação, com média de dez anos como docentes - $69 \%$ têm menos de dez anos de experiência. Quando perguntados sobre a quantidade de

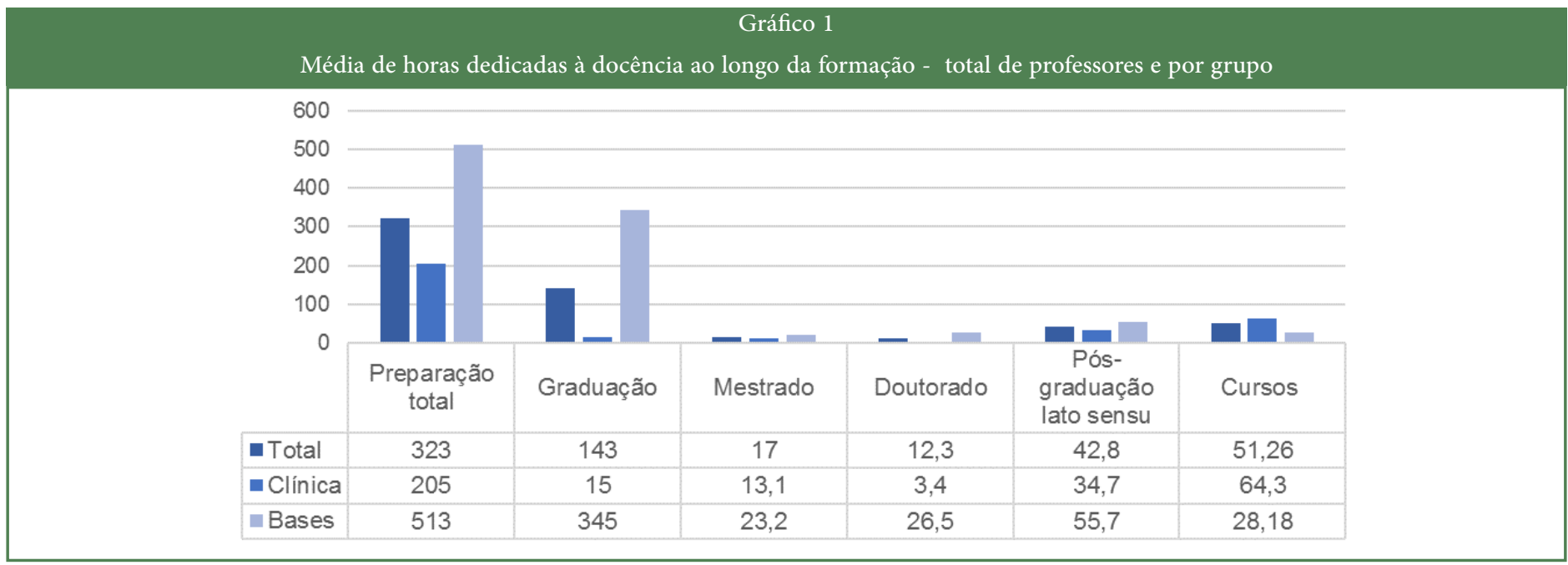

Fonte: Elaborado pelos autores. 
horas semanais dedicadas à docência, independentemente do estabelecido em contrato, observa-se uma média de 34 horas semanais, com $54 \%$ dos professores se dedicando 40 ou mais horas e $24 \%$ se dedicando 20 horas ou menos. Do tempo considerado, são gastas em média 8,7 horas dentro de sala de aula (67\% dedicando menos que dez horas), 4,7 horas em práticas fora da universidade, dez horas com preparação de aulas e correção de exercícios (66\% menos que dez horas) e 7,6 horas com pesquisa (68\% menos do que dez horas). Entre os $68 \%$ dos professores que se dedicam à pesquisa, $44 \%$ o fazem há mais de 15 anos.

Entre os professores entrevistados, $35 \%$ se dedicam exclusivamente à universidade. Dentre os $65 \%$ que não atuam com dedicação exclusiva, 94\% trabalham como médicos. Todos os professores em dedicação parcial possuem mais tempo de experiência em sua outra profissão do que como docente, com uma média de 18,2 anos de experiência na outra profissão ( $84 \%$ possuem mais de dez anos de experiência). Quanto ao tempo despendido semanalmente com a outra profissão, são dedicadas em média 28,8 horas, e $37 \%$ dedicam mais de 30 horas e $46 \%$ dedicam mais tempo à outra profissão do que à docência. No conjunto de professores entrevistados, $54 \%$ possuem em outra profissão sua principal fonte de renda, número que se eleva para $84 \%$ quando considerados apenas os que não trabalham de forma exclusiva como professores. Quando perguntados sobre qual seria sua profissão autodeclarada, $42 \%$ dos professores responderam que seria "médico"; 39\%, "professor"; 10\%, "professor e médico"; e 9\%, outras. Quanto à metodologia de ensino, 54\% se declararam tradicionais; $16 \%$, inovadores; e 30\%, nenhuma das opções dadas.

A atuação dos professores se dá de forma ainda mais diversa quando divididos nos dois grupos analisados. Enquanto $91 \%$ dos professores de bases trabalham exclusivamente com a docência, nenhum dos professores de clínica é exclusivo. Os professores de bases têm mais experiência, média de 13,5 anos contra 7,8 anos, e dedicam mais horas à docência, mais horas dentro de sala de aula e mais horas com preparação de aulas, como demonstrado no Gráfico 2. Enquanto $95 \%$ dos professores de bases possuem a docência como principal fonte de renda, apenas $14 \%$ dos professores de clínica a têm como fonte principal. Com relação à pesquisa,
95\% dos professores de bases realizam pesquisas, com experiência média de 15,4 anos e 14,8 horas de dedicação semanal, enquanto, entre os professores de clínica, $51 \%$ realizam pesquisas, com experiência média de 5,7 anos e 3,1 horas de dedicação semanal. Outra diferença marcante entre os dois grupos está na profissão autodeclarada: para $94 \%$ dos professores de bases, é a de "professor", ao passo que, entre professores de clínica, $69 \%$ se declaram como "médicos" e 17\% como "professores".

No último conjunto de dados, relativos à motivação, os professores foram perguntados sobre quais seriam as principais motivações para trabalhar na docência. Com base nas opções apresentadas, obtiveram-se os seguintes resultados: $75 \%$ para aptidão, prazer para $95 \%$, oportunidade de pesquisa para $70 \%$, remuneração para $23 \%$ e status para $23 \%$. Além dessas opções, $23 \%$ citaram de forma espontânea a vontade de aprender ou se atualizar; $14 \%$, o convívio com os estudantes; $9 \%$, a possibilidade de contribuir para a formação de novos médicos; e 5\%, a qualidade de vida e segurança financeira. Quando se compararam os professores dos ciclos clínico e básico, os dados foram semelhantes, com destaque apenas para a remuneração, apontada como fator motivador para $50 \%$ dos professores de bases em oposição a $6 \%$ entre os de clínica.

Quando questionados sobre os principais desafios enfrentados para a implementação dos novos currículos de Medicina, 39\% citaram problemas relacionados à formação dos professores; $26 \%$, a dificuldade de integrar os conteúdos e a interdisciplinaridade; $19 \%$, a cultura de ensino tradicional; $18 \%$, problemas relacionados à gestão do curso, entre outros. Quando perguntados se estariam preparados para os desafios enfrentados, $41 \%$ responderam que sim, $26 \%$ que não e $33 \%$ que estariam parcialmente preparados. Por fim, quando se perguntou se eles sentiam estimulados a procurar por preparo, $81 \%$ responderam que sim. Dentre os principais estímulos internos para essa busca, $28 \%$ apontaram a vontade de se aprimorar como professores; $18 \%$, o prazer na docência e temas relacionados; $11 \%$, a vontade de aprender sobre os conteúdos que ensinam; e 7\%; a possibilidade de ver o sucesso dos alunos formados. Quanto a estímulos externos, apenas $26 \%$ apontaram algum, destacando-se a progressão na carreira, citada por $18 \%$, e a pressão dos pares, apontada por $4 \%$.

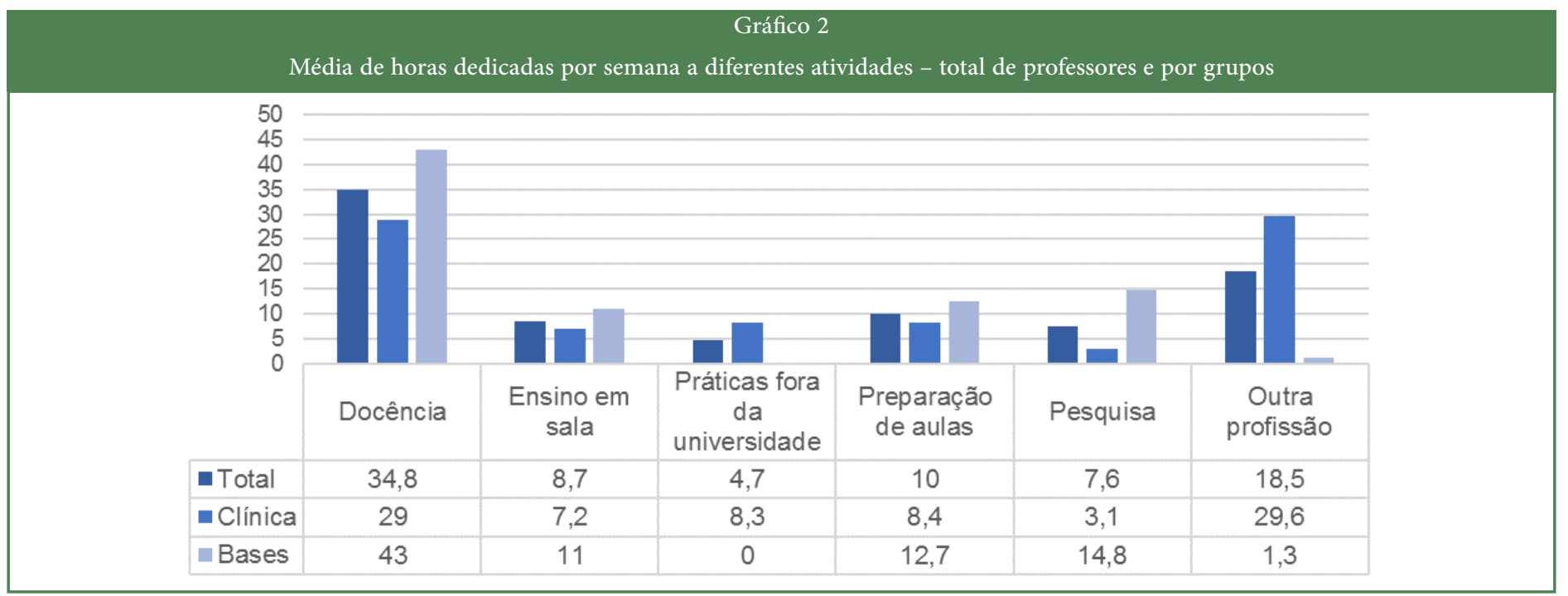

Fonte: Elaborado pelos autores. 


\section{Avaliação dos professores}

Os professores do curso que aceitaram participar da pesquisa foram avaliados por 203 alunos (84,58\% dos elegíveis), com notas em uma escala de 1 a 9 , tomando como base o desempenho geral do docente: 1 igual a muito ruim e 9 igual a muito boa. Atribuiu-se um total de 8.265 notas, com média de 6,98 e mediana de 7. O professor mais bem avaliado recebeu nota média de 8,46 , enquanto o pior obteve média de 4,60. De acordo com os alunos, 19,3\% têm um desempenho muito bom (média entre 8 e 9); 63,16\%, bom (média entre 6 e 8); e 17,54\%, médio (média entre 4 e 6). Os alunos não mencionaram nenhum professor com desempenho ruim ou muito ruim.

As características traçadas no perfil docente, apresentadas anteriormente, foram utilizadas para dividir os professores em diferentes grupos que, posteriormente, tiveram suas avaliações médias comparadas e testadas quanto à significância estatística. Entre as características testadas, relacionadas à formação, demonstraram significância o tempo decorrido desde a graduação, com 0,7 ponto em média maiores entre aqueles com menos de 20 anos de conclusão da graduação em relação ao restante; e o título de mestre, com 0,64 ponto em média maior para aqueles que não possuem o título. A Tabela 1 apresenta os valores relacionados à formação.

Quanto às características relacionadas com a atuação profissional, tiveram significância estatística a experiência como docente, com aqueles com mais de 20 anos de docência recebendo em média 1,45 ponto menor comparativamente àqueles com menor experiência, e a experiência na profissão que exerce paralelamente à docência, com média 0,61 ponto menor entre aqueles com mais de 20 anos de experiência. Os demais valores relacionados à atuação profissional encontram-se na Tabela 2.

Por fim, entre as características relacionadas com a motivação, foram estatisticamente significantes o prazer pela docência, em que os professores tiveram uma pontuação média de 1,73 ponto maior que os demais, e a aptidão, que conferiu uma média de 0,66 ponto maior àqueles que a indicaram esse fator. Os demais dados podem ser vistos na Tabela 3. Além das características relativas aos três eixos, dois grupos etários de professores também foram comparados, e a diferença entre as notas médias apresentou relevância estatística: professores com menos de 45 anos tiveram nota média de 7,22, 0,63 ponto maior que a média de 6,59 dos professores com idade superior ou igual a 45 anos (p-valor de 0,03888 ).

\section{DISCUSSÃO}

Perfil dos professores

O perfil encontrado na unidade de estudo se assemelha ao apontado na literatura sobre o assunto, principalmente quando considerado o grupo de professores do ciclo clínico. O perfil é semelhante àquele apontado no relatório da Cinaem ${ }^{7}$, em que predominam professores em regime de dedicação parcial à universidade, com renda proporcionada principalmente por outra profissão e com preparação didática constituindo uma parte reduzida de sua formação. Esse perfil, cuja mudança já era considerada urgente ao final da década de 1990, parece ter se desenvolvido muito pouco desde então, confirmando a dificuldade de desenvolvimento docente apontada na literatura.

Um dos principais fatores que levariam a essa dificuldade seria o fato de os docentes encararem a docência como profissão secundária, em detrimento de sua outra profissão ${ }^{14,17,24}$. Essa ideia fica reforçada a partir de certos dados levantados no estudo, como o maior tempo de experiência, o elevado número de horas dedicadas, a maior proporção

\begin{tabular}{|c|c|c|c|}
\hline \multicolumn{4}{|c|}{$\begin{array}{c}\text { Tabela 1 } \\
\text { Comparação entre as notas médias recebidas por diferentes grupos } \\
\text { de professores, de acordo com as características relacionadas à } \\
\text { formação para docência }\end{array}$} \\
\hline Variável & \multicolumn{2}{|c|}{ Valores } & p-valor \\
\hline Curso de graduação & Medicina & Outro & \\
\hline Nota média & 7,09 & 6,78 & $0,3867^{\mathrm{b}}$ \\
\hline Universidade onde se graduou & Privada & Pública & \\
\hline Nota média & 6,81 & 6,99 & $0,6222^{\mathrm{b}}$ \\
\hline Tempo de formado & $\geq 20$ anos & $<20$ anos & \\
\hline Nota média & 6,53 & 7,23 & $0,0206^{b}$ \\
\hline $\begin{array}{c}\text { Preparação para a docência na } \\
\text { graduação }\end{array}$ & Sim & Não & \\
\hline Nota média & 6,58 & 7,12 & $0,1684^{\mathrm{b}}$ \\
\hline $\begin{array}{l}\text { Horas dedicadas à docência na } \\
\text { graduação }\end{array}$ & $>200$ horas & $\begin{array}{l}\leq 200 \\
\text { horas }\end{array}$ & \\
\hline Nota média & 6,76 & 7,03 & $0,5440^{\mathrm{b}}$ \\
\hline $\begin{array}{l}\text { Interesse na docência durante a } \\
\text { graduação }\end{array}$ & Sim & Não & \\
\hline Nota média & 6,92 & 7,06 & $0,6429^{\mathrm{b}}$ \\
\hline Pós-graduação stricto sensu & Sim & Não & \\
\hline Nota média & 6,8 & 7,39 & $0,0596^{\mathrm{b}}$ \\
\hline Mestrado & Sim & Não & \\
\hline Nota média & 6,76 & 7,4 & $0,0405^{b}$ \\
\hline $\begin{array}{c}\text { Preparação para a docência no } \\
\text { mestrado }\end{array}$ & $>60$ horas & $\leq 60$ horas & \\
\hline Nota média & 7,15 & 6,69 & $0,1754^{a}$ \\
\hline Doutorado & Sim & Não & \\
\hline Nota média & 6,86 & 7,09 & $0,4341^{\mathrm{b}}$ \\
\hline $\begin{array}{c}\text { Preparação para a docência no } \\
\text { doutorado }\end{array}$ & $>60$ horas & $\leq 60$ horas & \\
\hline Nota média & 7,04 & 6,56 & $0,3055^{\mathrm{a}}$ \\
\hline Pós-graduação lato sensu & Sim & Não & \\
\hline Nota média & 6,95 & 7,06 & $0,7827^{\mathrm{b}}$ \\
\hline $\begin{array}{c}\text { Preparação para docência durante a } \\
\text { pós-graduação lato sensu }\end{array}$ & Sim & Não & \\
\hline Nota média & 6,88 & 6,95 & $0,8363^{\mathrm{a}}$ \\
\hline Cursos voltados para a docência & Sim & Não & \\
\hline Nota média & 6,77 & 7,09 & $0,3136^{\mathrm{b}}$ \\
\hline Preparação total para a docência & $>200$ horas & $\leq 200$ horas & \\
\hline Nota média & 6,99 & 7,02 & $0,8853^{\mathrm{b}}$ \\
\hline
\end{tabular}

${ }^{a}$ Teste t de Student; ${ }^{b}$ teste de Mann-Whitney. Valor de p considerado significativo abaixo de 0,05 .

Fonte: Elaborada pelos autores. 


\begin{tabular}{|c|c|c|c|}
\hline \multicolumn{4}{|c|}{$\begin{array}{c}\text { Tabela } 2 \\
\text { Comparação entre as notas médias recebidas por diferentes grupos } \\
\text { de professores, de acordo com as características relacionadas à } \\
\text { atuação profissional }\end{array}$} \\
\hline Variável & \multicolumn{2}{|c|}{ Dados } & p-valor \\
\hline Experiência como docente & $>20$ anos & $\leq 20$ anos & \\
\hline Nota média & 5,65 & 7,10 & $0,0171^{\mathrm{b}}$ \\
\hline $\begin{array}{c}\text { Horas semanais dedicadas à } \\
\text { docência }\end{array}$ & $\geq 40$ horas & $<40$ horas & \\
\hline Nota média & 6,84 & 7,14 & $0,2454^{b}$ \\
\hline Horas semanais em sala de aula & $\geq 10$ horas & $<10$ horas & \\
\hline Nota média & 6,92 & 7,01 & $0,6625^{\mathrm{b}}$ \\
\hline Preparação de aula & $>10$ horas & $\leq 10$ horas & \\
\hline Nota média & 6,69 & 7,11 & $0,2220^{\mathrm{b}}$ \\
\hline Dedicação exclusiva & Sim & Não & \\
\hline Nota média & 6,78 & 7,08 & $0,3710^{\mathrm{b}}$ \\
\hline Outra profissão & Médico & Outra & \\
\hline Nota média & 7,12 & 6,41 & $0,6603^{\mathrm{a}}$ \\
\hline $\begin{array}{l}\text { Docência como principal fonte de } \\
\text { renda }\end{array}$ & Sim & Não & \\
\hline Nota média & 6,7 & 7,2 & $0,0957^{\mathrm{b}}$ \\
\hline Experiência na outra profissão & $\geq 20$ anos & $<20$ anos & \\
\hline Nota média & 6,68 & 7,29 & $0,0040^{2}$ \\
\hline Horas semanais na outra profissão & $>20$ horas & $\leq 20$ horas & \\
\hline Nota média & 7,21 & 6,9 & $0,3545^{\mathrm{a}}$ \\
\hline Realiza pesquisa & Sim & Não & \\
\hline Nota média & 6,88 & 7,18 & $0,2794^{\mathrm{b}}$ \\
\hline Experiência com pesquisa & $>15$ anos & $\leq 15$ anos & \\
\hline Nota média & 6,88 & 6,89 & $0,9710^{\mathrm{a}}$ \\
\hline $\begin{array}{c}\text { Horas semanais dedicadas à } \\
\text { pesquisa }\end{array}$ & $\geq 10$ horas & $<10$ horas & \\
\hline Nota média & 6,58 & 7,14 & $0,1002^{\mathrm{a}}$ \\
\hline Profissão declarada & Professor & Outra & \\
\hline Nota média & 6,83 & 7,12 & $0,3342^{\mathrm{b}}$ \\
\hline
\end{tabular}

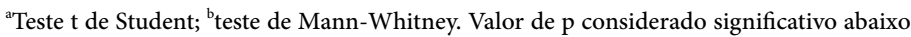
de 0,05 .

Fonte: Elaborada pelos autores.

da renda e, acima de tudo, a maior identificação do professor com a outra profissão, já que, como visto, mais professores se identificam como médicos do que como docentes. A falta de interesse por parte dos professores médicos em se tornarem professores ainda durante a sua graduação, detectada nos resultados da pesquisa, reforçaria essa falta de identificação e confirma resultados semelhantes encontrados em outras pesquisas $^{15,16}$. O desinteresse, como salientam Souza Filho e Naujorks ${ }^{15}$, seria alimentado pelo próprio curso de Medicina, em que o "alicerce didático não é contemplado" (p. 39), algo que os resultados da pesquisa também reforçaram, ao indicarem que $92 \%$ dos professores médicos não

\begin{tabular}{|c|c|c|c|}
\hline \multicolumn{4}{|c|}{$\begin{array}{c}\text { Tabela } 3 \\
\text { Comparação entre as notas médias recebidas por diferentes grupos } \\
\text { de professores, de acordo com as características relacionadas à } \\
\text { motivação para a docência }\end{array}$} \\
\hline Variável & \multicolumn{2}{|c|}{ Dados } & p-valor \\
\hline Remuneração & Sim & Não & \\
\hline Nota média & 7,14 & 6,92 & $0,5117^{\mathrm{b}}$ \\
\hline Pesquisa & Sim & Não & \\
\hline Nota média & 6,98 & 6,95 & $0,9444^{\mathrm{b}}$ \\
\hline Prazer & Sim & Não & \\
\hline Nota média & 7,07 & 5,34 & $0,0279^{b}$ \\
\hline Aptidão & Sim & Não & \\
\hline Nota média & 7,14 & 6,48 & $0,0210^{b}$ \\
\hline Status & Sim & Não & \\
\hline Nota média & 7,00 & 6,97 & $1,00^{\mathrm{b}}$ \\
\hline Preparado & Sim & Não & \\
\hline Nota média & 6,82 & 7,08 & $0,4945^{\mathrm{b}}$ \\
\hline Estimulado & Sim & Não & \\
\hline Nota média & 6,97 & 6,86 & $0,8299^{b}$ \\
\hline
\end{tabular}

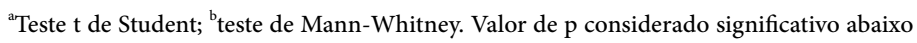
de 0,05 . Fonte: Elaborada pelos autores.

tiveram conteúdo voltado para a docência durante a formação.

Outro fator apontado na literatura como promotor de um distanciamento do docente das atividades de ensino seria a pesquisa, especialmente entre professores do ciclo básico que se dedicariam muito mais à pesquisa do que os do ciclo clínico. No entanto, pelo levantado, ela não parece exercer uma influência tão grande na atuação dos docentes quanto o trabalho em outra profissão.

Além do distanciamento e da falta da identificação com a docência, existiria uma dificuldade dos professores em se aprimorar e se adaptar aos novos currículos médicos, cada vez mais complexos. A maioria dos professores de Medicina não ignora mudanças curriculares por desinteresse, mas, muitas vezes, pela falta do conhecimento pedagógico necessário para compreendê-las ${ }^{18,25}$. Os resultados da pesquisa corroboram essa percepção, já que observamos, na unidade em estudo, uma proporção muito maior de professores se sentindo estimulados a mudar do que preparados para a mudança. Chama a atenção ainda o fato de que os próprios professores reconhecem os problemas na formação docente como o principal desafio a ser encarado nas mudanças curriculares.

Os problemas na formação ficam mais evidentes quando os professores mencionam de que forma aprenderam a ensinar. Apenas $21 \%$ citam cursos, graduação ou pós-graduação, valor menor em relação àqueles que relatam não ter aprendido e menos da metade daqueles que dizem ter sido por meio da prática em sala de aula.

Um avanço em relação ao apontado em pesquisas mais antigas, como o próprio relatório desenvolvido pela Cinaem, diz respeito à pósgraduação stricto sensu, que, no caso da unidade em estudo, foi cursada pela maioria dos professores, mesmo quando se analisaram os professores do ciclo clínico separadamente. Esse avanço, todavia, não representa uma

\begin{tabular}{l|l}
7 & REVISTA BRASILEIRA DE EDUCAÇC̃O MÉDICA \\
\hline 44 (3) : e096; 2020
\end{tabular} 
melhora significativa do ponto de vista de preparo didático, uma vez que os dados analisados confirmam que uma proporção muito pequena desses cursos é voltada para a preparação didática ${ }^{8,16,20}$.

Outro problema importante apontado pela literatura é a falta de estímulo ao aprimoramento dos professores ${ }^{14}$. Conforme os resultados da pesquisa apontam, embora a maioria dos professores se sinta estimulada a melhorar, a maior parte entende que os estímulos são apenas internos, não recebendo incentivos nem da universidade nem das autoridades da educação. Além disso, problemas relacionados à forma como o curso é gerido estiveram entre os mais citados como principais desafios para mudanças.

\section{Avaliação dos professores}

Os resultados encontrados na comparação entre as avaliações médias obtidas nos diferentes grupos de características rompem com o identificado na literatura sobre o tema ou mesmo com o que se tem como intuitivo. Era de se esperar que uma maior formação voltada para a docência, uma maior experiência e um maior tempo de dedicação levassem a diferenças significativas no desempenho percebido, com uma melhor avaliação dos professores que apresentassem essas características. Os resultados, todavia, mostraram não só que a diferença não chega a ser significativa, mas também que, em alguns casos, essas características estão associadas a um pior desempenho.

Entre as características cuja comparação resultou em médias com diferenças estatisticamente relevantes, temos um conjunto, formado por tempo de graduação, experiência como docente e experiência na outra profissão, que parece girar em torno de outra característica também avaliada e que demonstrou relevância estatística: a idade. O que os dados parecem indicar é que os benefícios trazidos por uma maior experiência em ensinar ou na profissão ensinada, ou mesmo maior experiência de vida em geral, não são suficientes para contrabalancear fatores como conflitos geracionais, adaptação a novos métodos ou mesmo o cansaço após décadas de profissão.

Pesquisas mostram mudanças na forma de as novas gerações pensarem, comunicarem-se e aprenderem, e o quanto isso pode tornar desafiador para professores de uma geração anterior o ato de ensinar ${ }^{26}$. Hoje os alunos, independentemente da capacidade intelectual, possuem baixa tolerância a longas leituras e exposições de temas e uma maior necessidade de interatividade e de senso de propósito no que está sendo aprendido $^{26-28}$. Tais características os colocam muitas vezes em conflito com a forma tradicional de ensino, pautada na emissão de conteúdo pelo professor com recepção passiva pelo aluno, conceituada por Freire como "educação bancária"26-29, e os diferenciam das gerações anteriores de alunos que atendiam ao ensino com um senso de dever e por isso eram menos questionadores ${ }^{27,28}$.

Além do conflito entre as diferentes visões de mundo e formas de lidar com o conhecimento das gerações mais antigas em relação às mais novas, características naturais relacionadas ao amadurecimento em uma profissão também podem ajudar a explicar as diferenças nas avaliações. Professores em início de carreira tendem a se entregar de forma mais emocional e entusiasmada ao trabalho, algo que vai sendo moderado com o tempo diante das demandas que a profissão impõe. Além disso, são mais flexíveis e adaptáveis, característica comum em jovens em início de carreira, em qualquer profissão ${ }^{30}$. Professores em fase mais avançada na carreira, por sua vez, já não dispõem de tanta energia e, por isso, usam de "sabedoria/experiência" para dividi-la entre a profissão e outras obrigações e interesses que desenvolveram ao longo da vida. Além da maior dificuldade em assimilar alterações na maneira de atuar, com a aposentadoria se aproximando, os professores mais experientes não sentem que colherão os frutos do esforço em mudar nem se sentem mais tão ameaçados por imposições hierárquicas demandando mudanças ${ }^{30}$.

Assim, temos uma geração de alunos mais questionadores exigindo mudanças na forma como são ensinados de forma que ela se adeque mais harmoniosamente com o modo como aprendem e interagem com o mundo à sua volta. Contudo, temos dois grupos de professores: um que já lida com o mundo de forma semelhante e que ainda assim está mais aberto a se adaptar a novas demandas e outro que enxerga o mundo de maneira diferente, que está menos aberto a questionamentos e que precisaria despender uma energia que possui em menor quantidade para se adaptar a algo que nem mesmo julga necessário. Por consequência, esperam-se um menor nível de conflito e um maior atendimento de expectativas pelo primeiro grupo, assim como uma maior capacidade de se comunicar e transmitir o conhecimento para a nova geração de alunos. Menor conflito emaior flexibilidade, aliados a um maior entusiasmo naqueles que estão se iniciando na profissão, podem explicar os resultados encontrados na pesquisa ${ }^{26-28,30}$.

A importância do entusiasmo com a profissão é reforçada pela análise das características relacionadas com a motivação que demonstraram relevância estatística. Os resultados da pesquisa mostram que professores que trabalham motivados pelo prazer em dar aulas e por se sentirem mais aptos para a docência recebem avaliação média consideravelmente maior que os demais.

A associação entre satisfação e performance é um dos temas mais estudados em pesquisas organizacionais desde o início do século $\mathrm{XX}^{31,32}$. As pesquisas partem de três pontos de vista: satisfação causa performance, performance causa satisfação ou que ambas são moderadas por outros fatores, como o salário e prêmios ${ }^{31,33}$. Apesar do grande número de pesquisas que testam os diferentes pontos, os resultados são divergentes em relação ao grau da relação existente entre satisfação e desempenho profissional, com algumas metanálises ${ }^{32-35}$ indicando que existe uma relação ao menos moderada e outras apontando uma relação mínima ${ }^{36}$. Alguns estudos, inclusive, não encontraram nenhuma relação ${ }^{37}$. Apesar das divergências, os estudos mais consistentes apontam para a existência da relação.

Algumas características encontradas em trabalhadores mais satisfeitos e que contribuem para um melhor desempenho são maior pontualidade, cooperação com colegas, confiabilidade e menores queixas e nervosismo ${ }^{35}$. A maior satisfação estaria associada ainda a menos faltas, redução da fadiga, promoção da saúde, menos greves e até diminuição de comportamentos contraproducentes como a sabotagem ${ }^{38}$. Embora as relações de trabalho no âmbito universitário se passem de forma diversa do empresarial, é provável que uma maior satisfação com o trabalho, também nesse ambiente, leve a características semelhantes. A presença dessas características pode justificar a melhor avaliação recebida pelos professores da unidade de estudo que têm prazer e aptidão como motivações para o trabalho.

A última característica que apresentou significância estatística foi o título de mestre, com professores detentores do título recebendo uma avaliação pior do que os que não fizeram mestrado. $\mathrm{O}$ resultado é muito 
significativo, principalmente quando se considera a importância dada pela legislação às especializações stricto sensu na formação de professores. A $\mathrm{LDB}^{19}$, principal documento legal sobre educação em nosso território, dedica apenas o artigo 66 ao tema da formação do professor universitário. De acordo com esse artigo, a preparação para o magistério superior se dará prioritariamente por meio de programas de mestrado e doutorado.

Embora exista essa aparente expectativa de que as especializações estejam preparando os professores para o ensino, na literatura é comum encontrar críticas ao modo como dá essa preparação. Joaquim, Boas et al. ${ }^{39}$ consideram que a LDB é negligente e que adota uma visão simplista ao ignorar a necessidade de melhor formação do professor na pós-graduação, além de criticarem a preponderância dada à pesquisa nas especializações. Na mesma linha, Martins, Azevedo et al. ${ }^{20}$ afirmam que as especializações teriam foco voltado para publicar artigos, participar de congressos e escrever livros, sendo mais determinantes para a melhora do currículo ou das chances em concursos do que para o aperfeiçoamento da capacidade didática. Já Garcia e Silva ${ }^{16}$ criticam o preparo pedagógico insuficiente e com caráter instrumental e genérico. Até mesmo a Comissão da Câmara de Educação, no parecer que fundamentou as DCN de 2014, reconhece que a preparação do docente das áreas da saúde precisa ir "muito além do que as disciplinas de 'metodologia do ensino superior' e 'didática' que os mestrados e doutorados propiciam" (p. 12).

Os resultados da pesquisa reforçam essas visões e vão além, uma vez que não só as especializações não melhoraram a avaliação dos professores, como também tiveram o efeito contrário. Isso leva ao questionamento se elas não poderiam estar atuando mais em tirar o foco do professor do ensino do que o preparando para a prática pedagógica, algo que merece um estudo mais aprofundado.

\section{CONCLUSÕES}

$\mathrm{Na}$ análise do perfil dos professores do curso, portanto, confirmam-se muitas das características apontadas na literatura como as principais dos professores de Medicina. A partir de uma análise dessas características e da percepção dos professores a respeito de sua própria atuação, podese considerar que a realidade da unidade em estudo se coaduna com a apontada para os demais cursos de Medicina do país. Os professores têm pouca identificação com a profissão, problemas na formação e se sentem menos estimulados do que deveriam para melhorar, assim como apontado em artigos sobre o tema.

Quando as características são avaliadas e testadas, pode-se perceber que não só é necessário mais tempo dedicado à formação para a docência, mas também maior qualidade nessa formação. A preparação do professor não pode se resumir à pós-graduação stricto sensu como a legislação espera, é imprescindível que o professor se aperfeiçoe continuamente não apenas para o conteúdo ensinado, mas também no que concerne ao modo de ensinar e interagir com os alunos, que possuem uma visão de mundo e maneiras de lidar com o conhecimento diversas dos professores, especialmente os de gerações anteriores. Os resultados da pesquisa indicam que, para um melhor ensino, é necessário que os professores estejam mais satisfeitos com a profissão, tenham uma formação didática melhor do que a conferida pelas especializações e que sejam preparados também para lidar com as mudanças contínuas nas gerações de alunos.

A pesquisa realizada tomou como base apenas um entre os diversos cursos de Medicina do país, e talvez seus resultados possam ter sido influenciados por características locais. Seria importante que a pesquisa fosse realizada em outros cursos para observação de divergências e comparação dos resultados. Além disso, novos questionamentos surgiram a partir da pesquisa e merecem ser aprofundados. Faz-se necessário investigar, por exemplo, por que a realização de mestrado está associada a uma pior avaliação ou por que a realização de cursos voltados para a docência ou um maior tempo de dedicação para preparação de aulas e para a universidade não resulta em avaliações melhores. Novas pesquisas precisam ser realizadas tanto no curso quanto em outras universidades para ampliar o entendimento sobre os fatores que determinam uma melhor prática pedagógica e assim contribuir para o longo processo de reformulação do ensino da Medicina.

\section{REFERÊNCIAS}

1. Araújo MH. As vozes do professor da Faculdade de Ciências Médicas da Universidade de Pernambuco sobre o processo curricular desenvolvido em 2002 e a identidade do novo médico [dissertação]. Recife: Universidade Federal de Pernambuco; 2011.

2. Marques F. Resgate crítico da Cinaem e das Diretrizes Curriculares Nacionais [monografia]. Campinas: Universidade Estadual de Campinas; 2012.

3. Koifman L. O modelo biomédico e a reformulação do currículo médico da Universidade Federal Fluminense. Hist Ciênc Saúde-Manguinhos (Online). 2001 [acesso em 30 out 2019];VIII(1):49-69. Disponível em: http://www.scielo.br/scielo.php?script=sci_arttext\&pid=S010459702001000200003\&lng=en.

4. Dias HS, Lima LD, Teixeira M. A trajetória da política nacional de reorientação da formação profissional em saúde no SUS. Ciênc Saúde Coletiva. 2013 [acesso em 30 out. 2019];18(6):1613-24. Disponível em: http://www.scielo.br/scielo.php?script=sci_arttext\&pid=S1413$81232013000600013 \& \operatorname{lng}=$ pt.

5. World Federation for Medical Education. The Edinburgh Declaration. Med Educ. 1988;22(5):481-2.

6. Karle H, Walton H, Lindgren S. The World Federation for Medical Education: History of the First Forty Years, 1972-2012. Copenhagen: World Federation for Medical Education; 2012.

7. Merhy EE, Aciole GG. Uma nova escola médica é possível? Aprendendo com a Cinaem 1 as possibilidades de construção de novos paradigmas para a formação em medicina. Pro-Posições. 2003;14(1):53-68.

8. Brasil. Ministério da Educação. Conselho Nacional de Educação. Câmara de Educação Superior. Resolução CNE/CES nº 4, de 7 de novembro de 2001. Institui Diretrizes Curriculares Nacionais do Curso de Graduação em Medicina. Diário Oficial da União, Brasília; 9 nov 2001; Seção 1, p. 38.

9. Brasil. Ministério da Educação. Conselho Nacional de Educação. Câmara de Educação Superior. Parecer CNE/CES no 116/2014 Diretrizes Curriculares Nacionais para o curso de Medicina. Diário Oficial da União, Brasília; 6 jun 2014; Seção 1, p. 17.

10. Brasil. Ministério da Saúde. Portaria Interministerial no 610, de 26 de março de 2002. Programa Nacional de Incentivo às Mudanças Curriculares nos Cursos de Medicina - Promed. Diário Oficial da União, Brasília; 26 mar 2002; Seção 1, p. 75.

11. Brasil. Ministério da Saúde. Ministério da Educação. Portaria Interministerial $\mathrm{n}^{\circ}$ 2.101, de 3 de novembro de 2005. Institui o

REVISTA BRASILEIRA DE EDUCAÇÃO MÉDICA

944(3) : e096; 2020 
Programa Nacional de Reorientação da Formação Profissional em Saúde - Pró-Saúde - para os cursos de graduação em Medicina, Enfermagem e Odontologia. Diário Oficial da União, Brasília; 3 nov 2005; Seção 1, p. 111.

12. Lampert JB, Costa NC, Perim GL, Abdalla IG, Aguilar-da-Silva RH, Stella RR. Tendências de mudanças em um grupo de escolas médicas brasileiras. Rev Bras Educ Med. 2009;33(1):19-34.

13. Lampert JB, Bicudo AM, organizadoras. 10 anos das Diretrizes Curriculares Nacionais dos cursos de graduação em Medicina. Rio de Janeiro: Associação Brasileira de Educação Médica; 2014.

14. Costa NM. Docência no ensino médico: por que é tão difícil mudar? Rev Bras Educ Med. 2007;31(1):21-30. doi: 10.1590/S010055022007000100004.

15. Souza Filho OC, Naujorks MI. O professor de Medicina da UFSM no contexto do mal-estar docente. Rev Bras Educ Med. 2005;29(1):34-40.

16. Garcia MA, Silva AL. Um perfil do docente de medicina e sua participação na reestruturação curricular. Rev Bras Educ Med. 2011;35(1):58-68. doi: 10.1590/S0100-55022011000100009.

17. Perim GL, Abdalla IG, Silva RA, Lampert JB, Stella RR, Costa NC. Desenvolvimento docente e a formação de médicos. Rev Bras Educ Med. 2009 [acesso em 30 out 2019];33(1):70-82. Disponível em: http://www.scielo.br/scielo.php?script=sci_arttext\&pid=S0100$55022009000500008 \& \operatorname{lng}=$ en\&nrm=iso.

18. Ten Cate O, Snell L, Mann K, Vermunt J. Orienting teaching toward the learning process. Acad Med. 2004;79(3):219-28.

19. Brasil. Lei Federal $n^{\circ}$ 9394, de 20 de dezembro de 1996. Estabelece as diretrizes e bases da educação nacional. Diário Oficial da União, Brasília; 23 dez. 1996.

20. Martins FA, Azevedo MT, Nonato SP. Docentes em formação e as significações produzidas em torno do ensino superior. Rev Docência do Ensino Superior. 2014;4:137-66.

21. Prodanov CC, Freitas EC. Metodologia do trabalho científico: métodos e técnicas de pesquisa e do trabalho acadêmico. 2a ed. Novo Hamburgo: Freevale; 2013.

22. Yin RK. Estudo de caso: planejamento e métodos. 2a ed. Porto Alegre: Bookman; 2001.

23. Gil AC. Como elaborar projetos e pesquisa. 4a ed. São Paulo: Atlas; 2002.

24. Rodriguez CA. As inovações do ensino superior e a formação do médico professor [dissertação]. Curitiba: Pontifícia Universidade Católica do Paraná; 2003.

25. Abreu Neto IP, Lima Filho OS, Silva LE, Costa, NM. Percepção dos professores sobre o novo currículo de graduação da Faculdade de Medicina da UFG implantado em 2003. Rev Bras Educ Med. 2006;30(3):154-0. doi: 10.1590/S0100-55022006000300006.

26. Soares AA, Marques CS, Almeida H, Nascimento EF, Moré RP. Os conflitos de geração no sistema de ensino superior sob prisma da epistemologia de coletivos de pensamento. In: Anais do XIV Colóquio Internacional de Gestão Universitária; 2014 dez 3-5; Florianópolis, Santa Catarina. Florianópolis: INPEAU (Instituto de Pesquisas e Estudos em Administração Universitária) - UFSC; 2014.

27. Twenge JM. Generational changes and their impact in the classroom: teaching Generation Me. Med Educ. 2009;43(5):398-405.

28. Gonçalves C. Gerações, tecnologia e educação: análise crítica do emprego educativo de novas tecnologias da informação e comunicação na educação superior da região metropolitana de Campinas [dissertação]. Americana: Centro Universitário Salesiano de São Paulo; 2012

29. Freire P. Pedagogia do oprimido. 67a ed. São Paulo: Paz e Terra; 2013.

30. Hargreaves A. Educational change takes ages: life, career and generational factors in teachers' emotional responses to educational change. Teach Teach Educ. 2005;21(8):967-83.

31. Queirós SF. Satisfação laboral e desempenho profissional: um estudo de caso para diagnóstico e intervenção [dissertação]. Porto: Universidade do Porto; 2015.

32. Wright TA, Cropanzano R. Psychological well-being and job satisfaction as predictors of job performance. J Occup Health Pscychol. 2000;5(1):84-94.

33. Petty MM, McGee GW, Cavender JW. A meta-analysis of the relationships between individual job satisfaction and individual performance. Acad Manage Rev. 1984;9(4):712-21.

34. Judge TA, Bono JE, Thoresen CJ, Patton GK. The job satisfactionjob performance relationship: a qualitative and quantitative review. Psychol Bull. 2001;127(3): 376-407.

35. Argyle M. Do happy workers work harder? The effect of job satisfaction on job performance. In: Veenhoven R, editor. how harmful is happiness? Consequences of enjoying life or not. Rotterdam: Universitaire Pers; 1989. p. 94-105.

36. Iaffaldano M, Muchinsky P. Job satisfaction and job performance: a meta-analysis. Psychol Bull. 1985;97(2):251-73.

37. Santos AG. Satisfação e desempenho: um estudo com empregados de contato [dissertação]. Coimbra: Universidade de Coimbra; 2016.

38. Gonçalves B. A motivação e satisfação no trabalho: importância, fatores, relacionamentos e consequências [dissertação]. Porto: Universidade Fernando Pessoa; 2017

39. Joaquim NF, Boas AAV, Carrieri AP. Estágio docente: formação profissional, preparação para o ensino ou docência em caráter precário? Educ Pesqui. 2013;39(2):351-65.

\section{CONTRIBUIÇÃO DOS AUTORES}

Vinícius Torres Leite participou do planejamento da pesquisa, da revisão bibliográfica, da coleta de dados em campo, da tabulação, da análise estatística de dados e criação de tabelas e figuras, da redação do texto e da padronização.

Paulo Ítalo Faria Lima Vazzi participou do planejamento da pesquisa, da revisão bibliográfica, da coleta de dados em campo, da tabulação e análise de dados, da revisão do texto e da padronização.

Marcos Barbosa Rodrigues de Moura e Larissa Santos Pereira participaram do planejamento da pesquisa, da revisão bibliográfica, da coleta de dados em campo, da tabulação de dados e da revisão do texto.

Theóphilo de Paiva Caldas Neto participou do planejamento da pesquisa, da revisão bibliográfica, da coleta de dados em campo e da revisão do texto.

Eduardo Henrique de Matos Lima orientou e supervisionou a pesquisa, apoiou o planejamento, orientou a coleta de dados e participou da análise de dados e da redação e revisão do texto.

Todos os autores participaram da construção científica do manuscrito, considerando as etapas de leitura e revisão.

$$
\begin{array}{l|l}
\text { REVISTA BRASILEIRA DE EDUCAÇÃO MÉDICA } \\
\hline 10 \text { (3) : e096; } 2020
\end{array}
$$




\section{CONFLITO DE INTERESSES}

Os autores declaram não haver conflito de interesses neste estudo.

\section{ENDEREÇO PARA CORRESPONDÊNCIA}

Eduardo Henrique de Matos Lima. Universidade Federal de São João del-Rei, Curso de Medicina - CCO, Rua Sebastião Gonçalves Coelho, 400, Chanadour, Divinópolis, MG, Brasil. CEP: 35501-296.

E-mail: eduardo.henrique@ufsj.edu.br 